\title{
Mutation in Cenes FBN1, AKT1, and LMNA: Marfan Syndrome, Proteus Syndrome, and Progeria Share Common Systemic Involvement
}

\author{
Tonmoy Biswas. ${ }^{1}$
}

\begin{abstract}
Genetic mutations are becoming more deleterious day by day. Mutations of Genes named FBN1, AKT1, LMNA result specific protein malfunction that in turn commonly cause Marfan syndrome, Proteus syndrome, and Progeria, respectively. Articles about these conditions have been reviewed in PubMed and Coogle scholar with a view to finding relevant clinical features. Precise keywords have been used in search for systemic involvement of FBN1, AKT1, and LMNA gene mutations. It has been found that Marfan syndrome, Proteus syndrome, and Progeria commonly affected musculo-skeletal system, cardiovascular system, eye, and nervous system. Not only all of them shared identical systemic involvement, but also caused several very specific anomalies in various parts of the body. In spite of having some individual signs and symptoms, the mutual manifestations were worth mentioning. Moreover, all the features of the mutations of all three responsible genes had been co-related and systemically mentioned in this review. There can be some mutual properties of the genes FBN $1, A K T_{1}$, and LMNA or in their corresponding proteins that result in the same presentations. This study may progress vision of knowledge regarding risk factors, patho-physiology, and management of these conditions, and relation to other mutations.
\end{abstract}

Keywords: Genetic mutation; Marfan syndrome; Proteus syndrome; Progeria; Gene FBN1; Gene AKT1; Gene LMNA; Musculo-skeletal system; Cardiovascular system; Eye; Nervous system (Source: MeSH, NLM).

About the author: Tonmoy Biswas is currently a final year medical student of MBBS (Bachelor of Medicine, Bachelor of Surgery) in Faridpur Medical College, University of Dhaka, Bangladesh. He is also a candidate of 'Masters of Bio-ethics and Clobal Public Health' in American University of Sovereign Nations (AUSN), Arizona, United states.

\section{Introduction}

The haploid human genome consists of 3 billion nucleotides but changes in one single base pair can result in dramatic physiological malfunctions.' Mutations are changes in the genetic sequence at different levels that cause diversity among organisms. ${ }^{2}$ This can be happened by way of a number of factors.

Mutation is common in all types of organisms which is chiefly classified in three types; deleterious mutation with harmful effect upon host, neutral mutation with no effect, and advantageous mutation for welfare of the organism. But, most of the non-neutral mutations are deleterious. ${ }^{2-3}$

If a deoxyribonucleic acid (DNA) repair mechanism fails, the physiological consequences of a mutation are quite inconstant, ranging from single cell death or cell carcinoma to hereditary genetic outcomes. Mutations in germline cells of human generally produce inheritable consequences, while mutation in somatic cells of human ordinarily only have outcomes affecting the individual in which the mutation occurs (National Council for Science and the Environment, Washington, DC. Available from: http://www.eoearth.org/view/article/159530/, updated 2014 April 10, cited 2014 April 18).

Every cell, in order to function properly, depends on thousands of proteins to function in the right places at the right times. Changes in DNA caused by mutation can cause errors in protein synthesis, creating partially or completely non-functional proteins which in combination ultimately could result in genetic disorders. 4
Records in human mutation databases are increasing day by day. ${ }^{5}$ Even about one hundred thousand diseases showed association with mutation of only 3,700 genes. ${ }^{6}$ Around 300 new "inherited disease genes" (and about 10,000 new mutations) are added to the record book in a year.' The Human Gene Mutation Database (HCMD) is a complete assortment of germline modifications in nuclear genes containing over 141,000 mutations identified in more than 5,700 different genes up to June 2013. ${ }^{8}$ The first genetic mutation was reported in the year 1977 in HGMD Professional database with a maximum entry of 13,490 in 2013. Among the entries Missense/Non-sense mutations are more than 82,000 (Human Gene Mutation Database. Available from: http://www.hgmd.cf.ac.uk/ac/hahaha.php, updated 2014 April 12, cited 2014 April 18)

Besides some common disorders, mutations sometimes report some rare diseases like progeria, Marfan syndrome (MFS), Mandibuloacral dysplasia (MAD), Loeys-Dietz syndrome, Wolff-Parkinson-White Syndrome, Ehlers-Danlos syndrome, Proteus syndrome, Cantu syndrome, etc. Some of them shows same prevalence pattern, some shows nearly same clinical features and presentations. But, in spite of knowing about affected proteins of mutation, the actual pathogenesis and course of the disease is not clear. Over a decade have passed after the completion of human genome project but the gene mutation diseases' treatment is still in a labyrinth. For a better treatment, pathogenesis should be discovered and to look through it, it is needed to track the effects of affected proteins which is reflects by common manifestations in different systems of the body. 
The reason for selecting these three genes is to study their little known pathophysiology. The documented similarities between them were wanted to compile in a review.

\section{Search Strategy and Selection Criteria}

A literature search was conducted using Google Scholar, PubMed (Medline), The Human Gene mutation Database, and Genetic Home of US national Library. Key word combinations included "Marfan syndrome clinical features", "Proteus syndrome features", "Progeria syndrome features", "Gene FBN1 mutation", "Gene AKT1 mutation", Gene LMNA mutation". One hundred thirty five articles were chosen for review. The inclusion criteria incorporated the articles on disease case reports, databases, review papers and original papers. The exclusion criteria were unavailability of any full article, unclear presentation, non-relevant study and reports of different languages other than English. The common features were assembled into this narrative review. This review follows the Preferred Reporting Items for Systematic Reviews and Meta-Analysis (PRISMA) Statement. ${ }^{9}$

\section{Gene FBN1, AKT1, LMNA and associated proteins} $F B N 1$ gene is located on chromosome 15915-21.3. ${ }^{10}$ This gene is $200 \mathrm{~kb}$ and divided into 65 exons. ${ }^{11}$ It encodes fibrillin-1, ${ }^{10}$ a large extracellular matrix glycoprotein which assembles in extracellular matrix. In this matrix, fibrillin- 1 binds to other molecules of it and other proteins to form 10-12 nm threadlike filaments called microfibrils. ${ }^{12}$ Microfibrils are main constituent of elastic fibers responsible for stretching and supporting many tissues of the body. It also store a protein called transforming growth factor beta (TCF- $ß$ ), a critical growth factor which helps in proliferation, differentiation, motility, and apoptosis of cells. Microfibrils help to regulate the availability of TCF- $\beta$, which is inactivated when stored in microfibrils and activated when released (National Library of Medicine, NLM, Genetic - FBN1. Available from: http://ghr.nlm.nih.gov/gene/FBN1, updated 2014 April 12, cited 2014 April 18).

AKT1 is located on chromosome 14932.32. It is also known as $P K B, R A C-P K$. This gene initiates for a protein called AKT1 kinase which is responsible for signaling in the cells for its growth, multiplication, stability and apoptosis (NLM, Genetic - AKT1. Available from: http://ghr.nlm.nih.gov/gene/AKT1, updated 2014 April 12, cited 2014 April 18).

In mouse, it is found that, during apoptosis, Akt is cleaved by caspases and mediates survival signals for protection against apoptosis. ${ }^{12}$ Signaling involving AKT1 kinase also appears to be vital for the usual growth and function of the nervous system. It has a role in cell-to-cell communication among neurons, neuronal survival, and the formation of memories. The AKT1 gene belongs to a class of genes known as oncogenes. ${ }^{13}$

The LMNA gene, also known as lamin $\mathrm{A} / \mathrm{C}$ is located on the long (q) arm of chromosome 1 at position 22. More precisely, the LMNA gene is located from base pair $156,082,545$ to base pair $156,140,088$ on chromosome $1 .{ }^{14,15}$ This gene translates some slightly diverse proteins called lamins; among them lamin A and lamin $C$ are common in the most body cells. These proteins have an almost duplicate sequence of amino acids. The small difference in the sequence makes lamin A longer than lamin C due to encoded by an extra exon. ${ }^{15}$ Lamins $\mathrm{A}$ and $\mathrm{C}$ are structural proteins called intermediate filament proteins that provide stability and strength to cells. Lamins A and C are scaffolding (supporting) components of the nuclear envelope. Specifically, these proteins are located in the nuclear lamina where it regulates the movement of molecules into and out of the nucleus. Between lamin A and C, only the lamin A protein must be processed from prelamin $A$ before becoming part of the lamina (NLM, Genetic - LMNA. Available from: http://ghr.nlm.nih.gov/ gene/LMNA, updated 2014 April 12, cited 2014 April 18).

\section{Mutation of the Gene and diseases}

Mutation in the Gene FBN 1 causes MFS, Ectopia lentis, Shprintzen-Goldberg syndrome, and Hereditary aortic aneurysm. A mutation in the $\mathrm{FBN}_{1}$ gene has also been identified with Weill-Marchesani syndrome, stiff skin syndrome, neonatal MFS, ${ }^{10,16}$ Juvenile idiopathic arthritis, and acromicric or geleophysic dysplasias. ${ }^{17}$

When mutation occurs in $A K T 1$ gene, it causes Proteus syndrome. AKT1 gene is an oncogene which can create breast, ovarian and colorectal cancer after mutation and may have some association with schizophrenia (NLM, Genetic - AKT1. Available from: http://ghr.nlm.nih.gov/gene/AKT1, updated 2014 April 12, cited 2014 April 18). Mutation in gene AKT1 may also causes endometrial carcinoma, ${ }^{18}$ bladder tumors, ${ }^{19}$ squamous cell carcinoma of lung,,$^{20}$ metastatic thyroid cancer, ${ }^{21}$ hepatocellular carcinoma, and acute leukemia, ${ }^{22}$ and many other tumors of the body. ${ }^{33}$

Mutations in the LMNA gene are related to a number of diseases, including Hutchinson-Gilford progeria syndrome (HGPS), limb girdle muscular dystrophy, familial partial lipodystrophy, Emery-Dreifuss muscular dystrophy, dilated cardiomyopathy, Charcot-Marie-Tooth disease. The mutated gene of lamin A that causes HGPS commonly known as progerin. ${ }^{23,24}$ Loss of lipid level, type-2 Diabetes mellitus, Dispersed Leukomelanodermic Papules, mandibuloacral dysplasia, lethal restrictive dermopathy, and atypical progeroid syndrome (APS) are also result of mutation in LMNA gene. ${ }^{128}$

In latter sections, MFS due to FBN1 mutation, Proteus syndrome due to AKT1 mutation and Progeria syndrome due to LMNA mutation is going to be discussed for common systemic involvement.

\section{Common systemic involvement of these gene mutations}

\section{Musculo-Skeletal system}

The phenotypes of MFS caused by FBN1 mutation, Proteus syndrome caused by AKT1 mutation and Progeria caused by LMNA mutation commonly results musculo-skeletal system abnormality.

In MFS, most of the visible signs are related to the skeletal system. Persons may have dolichostenomelia, arachnodactyly, abnormal indentation or protrusion of the sternum, stooped shoulders, malocclusions, ${ }^{25}$ abnormalities of the spine, ${ }^{26}$ presence of osteopenia (mainly in Marfan children), inadequate bone acquisition. ${ }^{28}$ The diagnosis of MFS relies on defined clinical criteria (Chent nosology), outlined by international expert. ${ }^{29}$ MFS causes the femoral head protruding into abnormally deep hip sockets (protrusio acetabuli). ${ }^{25}$ Protrusio acetabuli is a criterion for the diagnosis of MFS. If acetabuli is protruded for long 
time, it can cause anomaly in the hip joint and acetabular line. ${ }^{19}$ MFS also shows vascular smooth muscle cell apoptosis. ${ }^{30,31}$

In Proteus syndrome, skeletal abnormalities are the most frequent findings. ${ }^{35}$ Proteus syndrome shows megaspondylodysplasia, ${ }^{32}$ and cranio-facial abnormalities. ${ }^{33-35}$ Abnormal bony edges, bony invasions, joint immobility, and loss of overlying soft tissues have been reported in cases of it. ${ }^{33,34}$ Manifestations of Proteus syndrome include large sized finger in association with permanent medial or lateral deflection of one or more fingers, fusion of the bones in fingers or toes, or webbing of the soft tissues between the digits. ${ }^{35}$

In this condition, overgrowth of muscle and abnormally large muscle group with asymmetric muscle development are found..$^{36}$ Some smooth Muscle shows hyperplasia. ${ }^{37,38}$

In Progeria caused by LMNA mutation, skeletal defects include severe osteolysis, ${ }^{39}$ hypoplasia, dysplasia, and pathological fractures. It can cause severe alterations in osteogenesis, including craniofacial disproportion with a "plucked bird" appearance, ${ }^{40,43}$ short dystrophic clavicles, and thin and high pitched voice that may also occur. ${ }^{40,42,43}$ It also cause resorption of the clavicle, ${ }^{41-43}$ microvascular inadequacy, matrix abnormalities, bony maldevelopment, abnormally broad metaphyses and epiphyses, avascular necrosis of the femoral head..$^{42}$ The patients also have an extremely aged appearance and the limbs are usually thin and may be associated with stiff joints, and coxa valga. They also demonstrate "horse riding" stance and wide based shuffling gait. ${ }^{43}$ The ranges of motion for wrist, ankle, and hip rotation may decrease than normal..$^{41}$ There is chance of stooped shoulders, calcaneovalgus, genu valgum, kyphosis, or calcaneo varus. ${ }^{41,43}$ The muscle strength is preserved..$^{41,44,45}$

More specifically, MFS and Progeria both cause abnormal chest cavity where MFS can cause pectus excavatum or pectus carinatum, ${ }^{25}$ and Progeria may cause pyriform thorax with tapering of ribs. ${ }^{40-43}$ Osteopenia occurs in both of the cases which is axial or peripheral in MFS, ${ }^{37}$ and generalized in progeria. ${ }^{40-43}$ MFS also share pathological fracture and vascular smooth muscle cell defect with progeria. ${ }^{28,31,40,44}$ On the other hand, Proteus syndrome and progeria both have dental abnormalities where Proteus syndrome may cause alveolar dental ridges, ${ }^{35}$ and Progeria cause dental crowding with delayed teeth eruption. ${ }^{41-43}$

Some other regular features of musculo-skeletal system which are common in all these three mutations are discussed in the Table 1.

\section{Cardio-vascular system}

The MFS, Proteus syndrome and Progeria commonly cause cardio-vascular system abnormalities.

In MFS, cardio-vascular systems, usually diagnosed in young age is associated with poor prognosis. ${ }^{46}$ Cardiac arrhythmias, sudden cardiac death, endocarditis, $47-49$ are also cardiovascular manifestations of the MFS. Mitral Valve Prolapse is indicated as a useful diagnostic tool.47,50,51 The cardiovascular manifestations are the leading cause of death in MFS. ${ }^{51}$ MFS can also cause dilatation of the main pulmonary artery (MPA), dysfunction of the myocardium due to microfibrillar defect, ${ }^{51}$ abnormal reading on an electrocardiogram (ECG) but aortic wave reflection is not elevated in MFS. ${ }^{51-52}$ Infantile MS presents high morbidity with mitral regurgitation and heart failure. ${ }^{53}$ Clinical presentations of these manifestations comprise short breath, cardiac palpitations, abnormal heartbeats or angina pectoris with pain radiating to the back, shoulder, or arm. ${ }^{22}$ Myocardial infarction and bacterial endocarditis are some cardiac causes of death. ${ }^{54}$ In vascular system, there can be many types of defects in arterial wall including calcification. Rarely it shows axillary artery aneurysm. ${ }^{55,56}$

Proteus syndrome affects cardiac system less but sometimes it reports complex congenital heart disease and some myocardial abnormalities. ${ }^{57-59}$ Multiple superficial, visceral and vascular abnormalities are present in Proteus syndrome..$^{60}$ Vascular malformations have also been reported in this case with variety of types. They grow proportionately with the patient: they never regress, but they can expand. ${ }^{33}$ It can also cause cerebral vascular malformations, ${ }^{61}$ vascular tumors, portwine stains (PWS), and venous anomalies (varicosities, prominent veins). ${ }^{62}$

Table 1. Common Features Found in Marfan Syndrome, Proteus Syndrome, and Progeria Involving Musculo-skeletal System.

\begin{tabular}{|c|c|c|c|}
\hline Involvement of & Marfan syndrome $34,35,39$ & Proteus syndrome ${ }^{42-45,47}$ & Progeria ${ }^{48-52,54}$ \\
\hline Spine & $\begin{array}{l}\text { Abnormal curvature of spine (scoliosis), } \\
\text { kyphoscoliosis and other abnormalities. }\end{array}$ & $\begin{array}{l}\text { Vertebral dysplasia, asymmetry and en- } \\
\text { largement. }\end{array}$ & Severe scoliosis and decreased spinal flexion. \\
\hline $\begin{array}{l}\text { Skull and fa- } \\
\text { cial }\end{array}$ & High palate, small jaw & $\begin{array}{l}\text { Calvarial thickening, frontal bony promi- } \\
\text { nence, macrocephaly, hyperostoses of } \\
\text { the skull. Nasal bridge deformity, exter- } \\
\text { nal auditory canal overgrowth. }\end{array}$ & $\begin{array}{l}\text { Persistent open fontanelles, cranio-facial dispro- } \\
\text { portion, short and sculptured nose, large bald } \\
\text { head, small jaw. }\end{array}$ \\
\hline Joint & $\begin{array}{l}\text { Abnormal flexion, pain, early osteoar- } \\
\text { thritis. }\end{array}$ & Abnormal flexion & $\begin{array}{l}\text { Avascular necrosis of joint bones, Hip disloca- } \\
\text { tion. }\end{array}$ \\
\hline
\end{tabular}


In HGPS, the principal factor affecting mortality in individuals is cardiovascular disease. The description of the cardiovascular features of HGPS has proven to be quite consistent, ${ }^{63}$ that include prominent atherosclerosis and calcification of coronary arteries and others. The coronary artery disease leads to ischemic changes in the myocardium, including well-defined infarcts. In addition, it may also cause narrowing of the small intramural arteries, which may contribute to myocardial fibrosis. ${ }^{64}$ Chest $x$-rays shows cardiac enlargement and the electrocardiogram (ECG) shows right atrial hypertrophy sometimes. ${ }^{65}$ Sonographic and ECG evidence of myocardial ischemia is not common initially, but after a few years, echocardiograms and carotid Doppler sonography may show hypertrophy of the intimal layer of the internal carotid artery. Atherosclerotic changes, tricuspid valves with increased echo texture, left and right atrial dilatation, calcific aortic stenosis, cardiomegaly, and hypercholesterolemia are also seen in progeria. ${ }^{65,66}$ Death from cardiac complications at an average age of 14 years is usually preceded by angina pectoris and myocardial infarction, ${ }^{66}$ caused by progressive atherosclerotic disease. ${ }^{66}$ Children may die of myocardial infarction when they are found with diffuse loss of vascular smooth muscle and endothelial cells throughout their coronary arteries and replacement by fibrosis and adventitial thickening. ${ }^{67}$ If an old man has typical HGPS, he shows refractory congestive heart failure due to arteriosclerotic heart disease and hypertension, and also has arteriosclerosis obliterans. ${ }^{68}$ Sometimes loss of vascular smooth muscle cells (VSMCs) in the great vessels, veins, smaller arteries, and arterioles is seen in a case of progeria. There is spontaneous breaks in elastic structures, ${ }^{63,67}$ and prominent adventitial fibrosis to0. ${ }^{69}$ Vascular atherosclerotic changes may cause subdural hemorrhage leading to death in some cases. Small collagen fibrils in the atherosclerotic intima and media with extensive loss of mural smooth muscle cells in the aorta are also reported. ${ }^{\circ}$ Progeria can cause cerebral infarction and renal infarction. ${ }^{62}$

More specifically, MFS and Progeria both cause mitral valve calcification and increased echo texture..$^{51,63-65}$ MFS also cause mitral valve prolapse, regurgitation, fluttering of mitral leaflet, ${ }^{47}$ and severe rheumatic mitral stenosis. ${ }^{49}$ MFS and Proteus syndrome also share ventricular hypertrophy and dysfunction, ${ }^{50,51,65}$ systolic and diastolic abnormality,51,66 cardiac murmur, angina pectoris, congestive cardiac failure and myocardial infarction in common. ${ }^{52,54,66}$ On the other hand, Proteus syndrome and Progeria both can cause thickening of myocardial septum, cardiomyopathy, myocardial fibrosis and mass,,59,66 and abnormality in vascular endothelium. ${ }^{33,63,67}$
Some other regular features of cardio-vascular system which are common in all these three mutations are discussed in the Table 2.

\section{Eye}

The MFS, Proteus syndrome and HGPS commonly affect eye.

In MFS, eye complications such as lens dislocation or ectopia lentis occur in more than half the people who have MFS, earlier in women, ${ }^{73}$ and in some cases it is progressive (Mayo Clinic - MFS. Available from: http://www.mayoclinic.org/diseases-conditions/marfan-syndrome/basics/complications/con-20025944, updated 2014 April 07, cited 2014 April 18).71,72 Glaucoma is also common at a younger age which can damage the optic nerve. ${ }^{74,75}$ Sometimes MFS reports phthisis bulbi, bilateral or unilateral blindness..$^{74-76}$ The another ocular abnormality is enlargement of the globe, presumably caused by stretching of the tunica scleralis, and the zonular fibers. ${ }^{71}$ Some studies suggest prevalence of retinal detachment and some suggest prevalence of ectopia lentis. This variation recommend other genotype-phenotype relationships exist which may account for differences in ocular manifestations of MFS.73

The ocular manifestations of a Proteus syndrome are due to severe maldevelopment and malfunction of the neuroretina. Epibulbar tumors are recorded most commonly, ${ }^{76}$ while periorbital exostoses are infrequent, 77,81 extraocular tendons and posterior segment involvement can be seen in a case of Proteus syndrome presenting with vertical strabismus secondary to a fibrous tumor within the superior oblique tendon. ${ }^{88,79}$ Sometimes myopia associates with mild calcific band, abnormal vitreous structure, vitreous hemorrhage, and a resolved serous retinal detachment in a patient of Proteus syndrome. ${ }^{81}$ The oncogene of Proteus syndrome may show some overgrowth syndromes in eyes. ${ }^{81}$ Sometimes epibulbar cystic lesions with nodular gliosis are also reported in this condition. ${ }^{81}$

In Progeria, loss of eye brows and eye lashes with prominent eyes is common in the early childhood. ${ }^{43,83}$ Eyelid retractions, lagophthalmos, superior sulcus deformity, upper lid lag in down gaze, and poor pupillary dilatation are also reported. In the HGPS, eyes look prominent (pseudoproptosis) probably due to lid retraction, although there is no true proptosis. Superior sulcus deformity may also occur due to lipodystrophy of the orbital fat. Patients with HGPS do not develop other ocular features associated with aging, such as presbyopia, arcus senilis or age-related macular degeneration. Other rare ocular

Table 2. Common Features Found in Marfan Syndrome, Proteus Syndrome, and Progeria Involving Cardio-vascular System.

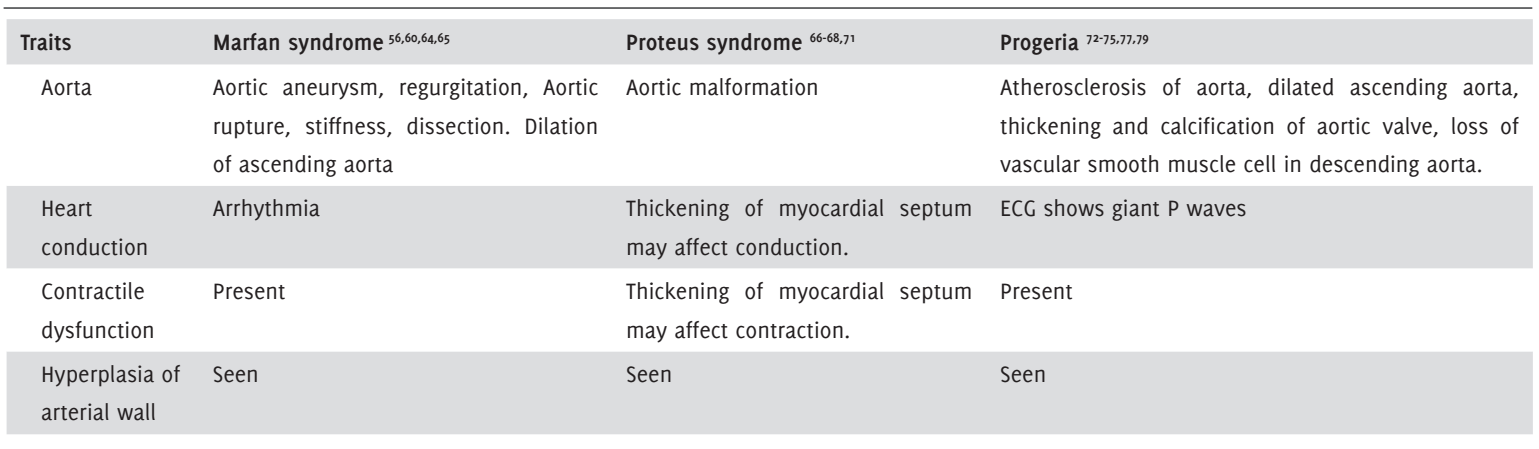


manifestations of the HGP syndrome are bands of skin running from the upper lid to the cornea, senile ectropion, ptosis with Marcus-jaw-winking phenomenon, dry-eye syndrome, and iridocorneal adhesions. ${ }^{83-85}$

More specifically, MFS and Proteus syndrome both cause optic nerve damage, ${ }^{74,75}$ and the former can also cause hypoplasia and papilledema of optic nerve. ${ }^{79,82}$ Proteus syndrome and Progeria both have features of nystagmus or nystagmoid movements..$^{7,83}$

Some other regular features of eye which are common in all these three mutations are discussed in the Table 3.

\section{Nervous system}

The MFS, Proteus syndrome and Progeria commonly cause nervous system abnormalities.

In MFS, the most common and classic neurological manifestations are cerebrovascular. ${ }^{86,87}$ Patients with MFSmay have a subarachnoid hemorrhage or intracranial aneurysm, ${ }^{88}$ and near total erosion of a pedicle. Dural ectasia can be added to the list of pleiotropic manifestations of the MFS. ${ }^{89}$ There is probability of heterogeneous involvement of other components of Extra Cellular Matrix microfibrils at the basis of this cerebrospinal manifestation. ${ }^{90,91}$ Dural ectasia with bone erosion which are often reported in this condition can be associated with severe postural headache secondary to spontaneous intracranial hypotension resulting from cerebrospinal fluid leaks caused by underlying fibrillinopathy. ${ }^{91-93} \mathrm{It}$ is recognized as a potential complication in children with MFS, ${ }^{93}$ and also reported with severe back pain in adults. ${ }^{94,95}$ When neural symptoms or findings do occur they may be related to stretching and traction mechanisms. ${ }^{91}$

Proteus syndrome often presents hemimegalencephaly with high incidence of other brain anomalies. ${ }^{96,97}$ These include hypoplasia of the corpus callosum and crus cerebri, grey and white matter calcification and cortical migration/organisational disorders. ${ }^{96}$ Neurologic sequelae caused by vertebral anomalies are reported to0.98.99 Proteus syndrome has evidence to develop pinealoblastoma, Dandy-Walker malformation, corpus callosal abnormalities, periventricular calcification, hypodense periventricular white matter, and mental deficiency. Hemimegalencephaly is not a finding in this entity; reported abnormalities include hydrocephalus, porencephaly, cerebral calcifications, and polymicrogyria. Additional Central Nervous
System (CNS) findings are thought to be the sequelae of vascular dysplasia, and include infarcts, atrophy, porencephaly, and calcifications. ${ }^{100}$ Some neurological defects like hydrocephaly, lissencephaly, partial agenesis of the corpus callosum are also reported with the Proteus syndrome. ${ }^{101}$ It may cause paraspinal hamartoma. ${ }^{99}$ Protuberance of the skull, ${ }^{102}$ structural and functional asymmetry of the central nervous system, ${ }^{103}$ hydrocephalus and mental retardation are also some features of proteus syndrome. ${ }^{102}$ Epilepsy and ohtahara syndrome is diagnosed in children affected by Proteus syndrome associated with infantile spasms, myoclonia, and partial epilepsy in newborn infants. ${ }^{97}$

In HGPS, diffuse encephalopathy, and Pseudotumor cerebri has been reported. ${ }^{41}$ Even a mild head injury can cause intracranial pathology in a progeria patient. Progressive atherosclerosis of intracranial vessels is responsible for formation of the hematomas in this condition. ${ }^{104,105}$ In progeria, motor and mental development is normal, as are intelligence. ${ }^{106}$ But there may be a low-frequency conductive hearing loss. ${ }^{107}$

There is chance of Peripheral neuropathy, ${ }^{108}$ cerebrovascular disease of aging in this age related disease, progeria. ${ }^{109}$

More specifically, MFS and Progeria both may cause headache, ${ }^{91-93,104}$ and do not have any mental retardation. ${ }^{105,106}$ MFS and Proteus syndrome both have spinal cord involvement where MFS may cause spinal Cerebro-spinal Fuild (CSF) leaks, spinal arachnoid diverticula, trauma, and congenital enlargement of spinal canal, ${ }^{90,91,94}$ and Proteus syndrome may cause spinal stenosis, paraspinal tumor, and spinal cord compression. ${ }^{98,99}$ On the other hand, seizures in seen in both Proteus syndrome and Progeria. ${ }^{100,102,104}$

Some other regular features of nervous system which are common in all these three mutations are discussed in the Table 4.

\section{Not shared systemic phenotypes}

MFS often presents spontaneous recurrent or bilateral pneumothorax, ${ }^{110}$ congenital malformations, ${ }^{111}$ pneumonia, bronchiectasis, emphysematous bullae, upper lobe fibrosis, aspergilloma and other lung related disorders. ${ }^{110-114}$ Patients may have lower values of Forced Vital Capacity and Total Lung Capacity and other spirometric values, ${ }^{115}$ with a decrease in carbon monoxide transfer factor, and lung elastic recoil. ${ }^{115}$ Other Lesser known areas of involvement are renal and dermatologic. ${ }^{11,117}$

Table 3. Common Features Found in Marfan Syndrome, Proteus Syndrome, and Progeria Involving Eye.

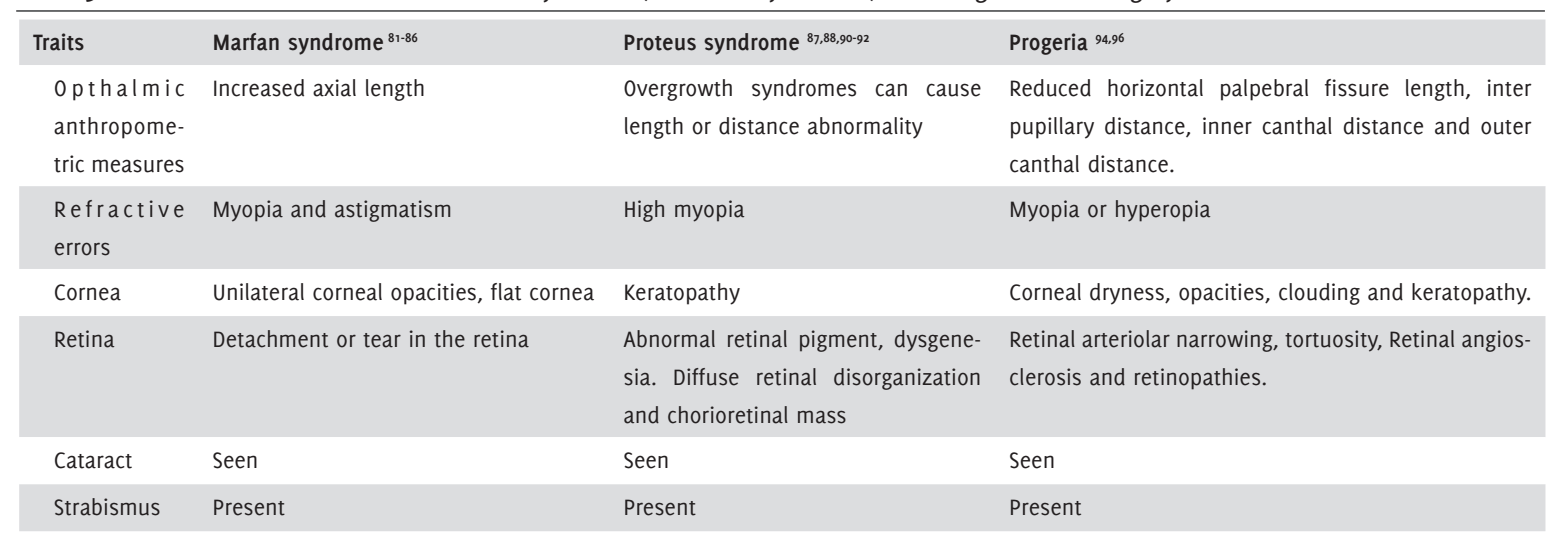


In proteus syndrome, Patients most commonly show bilateral ovarian serous cystadenomas, mesothelioma, and papillary carcinoma of the thyroid. ${ }^{118}$ Connective tissue nevus and brownish epidermal nevus in various region, 33,119 benign and malignant tumors and hamartomas are also seen in proteus syndrome. Commonly encountered tumors include hemangiomas, lymphangiomas, lipomas, epithelial tumor of the female genital tract, testicular and paratesticular tumors. ${ }^{119}$ Four types of abnormal fat may occur in Proteus syndrome: lipomas, lipohypoplasia, fatty overgrowth, and partial lipohyperplasia. There may be Fatty matter infiltration, Subependymal nodules, and Parenchymal distortion. Other rare tumors include Meningioma, Parotid monomorphic adenoma, Astrocytoma, optic nerve tumor, Pinealoma, Breast intraductal papilloma, Leiomyoma, Endometrial carcinoma, and giant kidney cysts. Multiple tumors in the same patient are often seen in proteus syndrome, ${ }^{33}$ with distal renal tubular acidosis and nephrocalcinosis, dilated and tortuous renal veins with possible calcifications. ${ }^{120}$

Progeria can cause low weight, vertical midline groove in the chin, sclerodermatous skin, reduced subcutaneous fat, ${ }^{121}$ prominent superficial veins, dyspigmentation, and alopecia of skin. ${ }^{122}$

A progeria case may present some biochemical abnormalities like hypoaminoacidemia, hyperaminoaciduria, increased radioactive lodine uptake in thyroid, and other abnormalities in blood. ${ }^{123}$

Progeria patients may be seen to sleep with open eyes, labial weakness, and nasal speech affecting speech fluency. ${ }^{43}$ Localized glomerulosclerosis, tubular atrophy, mesengial matrix growth, papillary adenoma are shown in older cases. ${ }^{124}$

\section{Vision of future research}

The genes responsible for the three diseases are not known to interact, so the possibility of mutation in any of them affecting functions of the other two is quite unlikely. However, recent studies suggest that mutations in the penultimate exon of $\mathrm{FBN}_{1}$ (in the 3 ' terminus) give rise to a neomorphic phenotype leading to a condition known as Wiedemann-Rautenstrauch syndrome, ${ }^{125} \mathrm{a}$ rare disorder characterized by overlapping of the clinical manifestations of both marfan's syndrome and progeroid syndrome.
It has been suggested that, this rare subgroup of MFS, comprised of congenital lipodystrophy, a neonatal progeroid appearance, ${ }^{126}$ and a progressive clinical course with early lethality, should be referred to as marfanoid-progeroid syndrome. ${ }^{127}$ Evidence of involvement of any mutation in the LMNA gene, the one associated classical progeria has not been unveiled till now. ${ }^{125}$ Any association of mutation in the AKT1 gene with the aforementioned circumstances is yet to be explored.

\section{Conclusion}

Genetic mutation is day by day increasing entries in the disease directory and started threatening the mankind like never before. MFS, Proteus syndrome, and Progeria are one of the most recognized mutation related diseases caused by mutation of FBN1, AKT1, and LMNA genes correspondingly. If we go through the Clinical features and systemic involvements of these mutations, we can find common involvement of musculo-skeletal system, cardiovascular system, eye, and nervous system. In musculo-skeletal system, deviations of spinal curvature, abnormalities in the extremities, skull, and facial bones are reported in all the three mutations. All cause abnormal flexion and limited range of motion of joints. In cardiovascular system, all the three mutations have reported abnormality of the aorta and cardiac conductive system. Contractile dysfunction of heart and hyperplasia of arterial wall have been seen in common too. In case of eye, MFS, Proteus syndrome, and progeria share many clinical features. All cause cataract, strabismus, and refractive errors along with same kind of retinal and corneal abnormalities. These mutations also have described some common nervous system features where all cause meningeal abnormalities, neurovascular abnormalities, congenital and developmental abnormalities. Stroke has been seen in all the three cases too. Though the mentioned mutations have certain individual unique characteristics too, the outcomes indicate that there can be some relation among the proteins related to these mutations, or among the genes of which modification occurs. The results of this review will enrich the field of genetic research and medicine. Furthermore, this study can help to acknowledge the reported sign it symptoms of three diseases and inter-relation among them. Additionally, it is recommended to have more attention in this field.

Table 4. Common Features Found in Marfan Syndrome, Proteus Syndrome, and Progeria Involving Nervous System.

\begin{tabular}{|c|c|c|c|}
\hline Traits & Marfan syndrome $97,98,100,102-107$ & Proteus syndrome ${ }^{111-113}$ & Progeria $50,116,118$ \\
\hline Stroke & Seen & Seen & Seen \\
\hline Meninges & $\begin{array}{l}\text { Dural ectasia, hernia of meninges or } \\
\text { meningocele }\end{array}$ & Meningioma & Meningeal hematoma. \\
\hline $\begin{array}{l}\text { Congenital CNS } \\
\text { abnormality }\end{array}$ & Present & Present & Present \\
\hline Developmental & Present & Present & Present \\
\hline
\end{tabular}




\section{References}

1. Suzanne Clancy; Genetic Mutation: Nature Education; Citation: Clancy, S. Ceneticmutation. Nature Education-2008: 1(1):187

2. Laurence Loewe. Genetic Mutation: Nature Education; Citation: Loewe, L. Genetic mutation. Nature Education-2008; 1(1):113

3. Eyre-Walker, A., Keightley. The distribution of fitness effects of new mutations. NatRev Genet.2007 Aug; 8, 610-18

4. Sawyer SA, Parsch J, Zhang Z, Hartl DL. "Prevalence of positive selection among nearly neutral amino acid replacements in Drosophila". Proc. Natl. Acad. Sci. U.S.A. (2007) 104 (16): 6504-10.

5. Mark P. Miller, Sudhir Kumar. Understanding human disease mutations through the use of interspecific genetic variation. Oxford Journals; Hum. Mol. Genet. (2001) 10 (21): 2319-2328.

6. Chen JM1, Férec C, Cooper DN. Revealing the human mutome. Clin Cenet. 2010 0ct; $78(4): 310-20$.

7. Cooper DN1, Chen JM, Ball EV, Howells K. Genes, mutations, and human inherited disease at the dawn of the age of personalized genomics. Hum Mutat. 2010 Jun;31(6):631-55.

8. Peter D. Stenson, Matthew Mort, Edward V. Ball, Katy Shaw, Andrew D. Phillips, and David N. Cooper et al. The Human Gene Mutation Database: building a comprehensive mutation repository for clinical and molecular genetics, diagnostic testing and personalized genomic medicine; Hum Genet. 2014; 133: 1-9.

9. Elizabeth A. Putnam, Hui Zhang, Francesco Ramirez ¿t Dianna M. Milewicz. Fibrillin-2 (FBN2) mutations result in the Marfan-like disorder, congenital contractural arachnodactyly; Nature Genetics 11, 456 - 458 (1995)

10. Biery NJ, Eldadah ZA, Moore CS, Stetten G, Spencer F, Dietz HC. "Revised genomic organization of $\mathrm{FBN}_{1}$ and significance for regulated gene expression". Cenomics (May, 1999) 56 (1): 70-7.

11. Handford PA; "Fibrillin-1, a calcium binding protein of extracellular matrix". Biochim. Biophys. Acta (2001). 1498 (2-3): 84-90. PMID 11108952

12. LMNA lamin A/C [Homo sapiens (human)]; Gene ID: 4000, updated on 13-Apr-2014; NCBI.

13. Reimer Stick. The gene structure of Xenopus nuclear lamin A: A model for the evolution of A-type from B-type lamins by exon shuffling; Springer-verlag; Chromosoma; August 1992, Volume 101, Issue 9, pp 566-574

14. P. Robinson and M. Godfrey. The molecular genetics of Marfan syndrome and related microfibrillopathies; Med Cenet. Jan 2000; 37(1): 9-25. PMCID: PMC 1734449

15. Wilson $B T 1$, Jensen $S A$, McAnulty $C P$, Brennan $P$, Handford PA. Juvenile idiopathic arthritis, mitral valve prolapse and a familial variant involving the integrin-binding fragment of FBN1. Am J Med Genet A. $2013 \mathrm{Au}$ g; $161 \mathrm{~A}(8): 2047-51$

16. $K$ Shoji, K Oda, S Nakagawa, S Hosokawa. The oncogenic mutation in the pleckstrin homology domain of AKT1 in endometrial carcinomas; British Journal of Cancer (2009) 101, 145-148.

17. J M Askham, F Platt, P A Chambers, H Snowden, C F Taylor and M A Knowles. AKT1 mutations in bladder cancer: identification of a novel oncogenic mutation that can co-operate with E17K; Oncogene (2010) 29, 150-155 18. Natasha Rekhtman, Paul K. Paik, Maria E. Arcila. Clarifying the Spectrum of Driver Oncogene Mutations in Biomarker-Verified Squamous Carcinoma of Lung: Lack of EGFR/KRAS and Presence of PIK 3 CA/AKT1 Mutations; Clin Cancer Res February 15, 2012,18;1167

19. Julio C. Ricarte-Filho, Mabel Ryder, Dhananjay A. Chitale, Michael Rivera. Mutational Profile of Advanced Primary and Metastatic Radioactive Iodine-Refractory Thyroid Cancers Reveals Distinct Pathogenetic Roles for BRAF, PIK3CA, and AKT1; Cancer Res June 1, 2009 69; 4885

20. M S Kim, E G Jeong, N J Yoo and S H Lee. Mutational analysis of oncogenic AKT E17K mutation in common solid cancers and acute leukaemias; British Journal of Cancer (2008) 98, 1533-1535.

21. Capell BC, Collins FS. "Human laminopathies: nuclei gone genetically awry". Nat. Rev. Genet. (December 2006). 7 (12): 940-52.

22. Rankin J, Ellard S. "The laminopathies: a clinical review". Clin. Genet. (October 2006). 70 (4): 261-74.

23. Van de Velde, S; Fillman, R; Yandow, S. Abstract of "Protrusio acetabuli in Marfan syndrome. History, diagnosis, and treatment.". The Journal of bone and joint surgery. American volume (March 2006) 88 (3): 639-46.

24. Lesley C. Adès, Darshikka, Sreetharan, Ella Onikul, Vivienne Stockton, Karen C, Watson et al. Segregation of a novel FBN1 gene mutation, G1796E, with kyphoscoliosis and radiographic evidence of vertebral dysplasia in three generations; Amer. Jour. Mol. Gen. First published online: 27 MAR 2002; DOI: 10.1002/ajmg. 10333

25. Van de Velde S, Fillman R, Yandow S. Protrusio acetabuli in Marfan syndrome. History, diagnosis, and treatment; J Bone Joint Surg Am. 2006 Mar;88(3):639-46.

26. Kohlmeier L, Gasner C, Bachrach LK, Marcus R. "The bone mineral status of patients with Marfan syndrome". Journal of Bone and Mineral Research (October 1995) 10 (10): 1550-1555. PMID 8686512

27. Loeys BL, Dietz HC, Braverman AC, Callewaert BL, De Backer J, Devereux RB et al. The revised Chent nosology for the Marfan syndrome. J Med Genet. 2010 Jul; $47(7): 476-85$

28. Francesco Ramirez, Harry C Dietz; Marfan syndrome: from molecular pathogenesis to clinical treatment Curr. Opin. Genet. Dev. 17 (2007) 252-258 29. Maria Nataatmadja, Malcolm West, Jenny West, RN; Kim Summers. Abnormal Extracellular Matrix Protein Transport Associated With Increased Apoptosis of Vascular Smooth Muscle Cells in Marfan Syndrome and Bicuspid Aortic Valve Thoracic Aortic Aneurysm; Circulation. 2003; 108: II-329-II-334.

30. P E. M. Azouz, T. Costa, N. Fitch. Radiologic findings in the proteus syndrome; Pediatric Radiology; October 1987, Volume 17, Issue 6, pp 481-485; Print ISSN: 0301-0449. Online ISSN: 1432-1998

31. M. Michael Cohen Jr. Proteus syndrome: An update; American Journal of Medical Genetics Part C: Seminars in Medical Genetics; Special Issue: Overgrowth Syndrome: An Update; (August 2005) 137C- 1- 38-52

32. J A R Tibbles, M M Cohen Jr. The Proteus syndrome: the Elephant Man diagnosed; British Medical Journal; SEP, 1986; VOLUME 29313

33. Carlos A. Jamis-Dow, Joyce Turner, Leslie G. Biesecker, and Peter L. Choyke et al. Radiologic Manifestations of Proteus Syndrome; Radiological Society of North America; July 2004; 24: 4

34. Joyce T. Turner, M. Michael Cohen Jr and Leslie G. Biesecker. Reassessment of the Proteus syndrome literature: Application of diagnostic criteria to published cases. American Journal of Medical Genetics Part A; (October 2004): 130A: 2: (111-122).

35. B. Newman, A. H. Urbach, D. Orenstein, P. S. Dickmann. Proteus syndrome: emphasis on the pulmonary manifestations: Pediatric Radiology; (June 1994): 24: 3: (189-193)

36. Teresa Costa, Naomi Fitch, E. Michael Azouz. Proteus Syndrome: Report of Two Cases With Pelvic Lipomatosis; Official journal of the American Academy of Pediatrics; Pediatrics Vol. 76 No. 6 December 1, 1985 pp. 984 -989 37. Raoul C.M. Hennekam. Hutchinson-Gilford progeria syndrome: Review of the phenotype; American Journal of Medical Genetics Part A; Special Issue: Thirteenth Annual Robert J. Corlin Conference on Dysmorphology; Facial and Oral Structures: Molecular Perspectives; (December 2006) Volume 140A, Issue 23, pages 2603-2624.

38. Giselle Helena de Paula Rodriguesa, Izilda das Eiras Tâmegaa, Gustavo Duqueb, Vicente Spinola Dias Netoa. Severe bone changes in a case of Hutchinson-Gilford syndrome; Annales de Cénétique; Volume 45, Issue 3 , July-September 2002, Pages 151-155

39. Melissa A. Merideth, Leslie B. Cordon, Sarah Clauss. Phenotype and Course of Hutchinson-Gilford Progeria Syndrome; N Engl J Med 2008; 358:592-604. 40. Leslie B. Gordon, Kathleen M. McCarten, Anita Giobbie-Hurder. Disease Progression in Hutchinson-Gilford Progeria Syndrome: Impact on Growth and Development; Official journal of the American Academy of Pediatrics; Pedia- 
trics (October 1, 2007) Vol. 120 No. 4 pp. $824-833$

41. P K Sarkara, R A Shintonb. Review: Hutchinson-Guilford progeria syndrome; Postgrad Med J 2001;77:312-317

42. Jinqiu Zhang, Qizhou Lian, Guili Zhu, Fan Zhou, Lin Sui, Cindy Tan. A Human iPSC Model of Hutchinson Gilford Progeria Reveals Vascular Smooth Muscle and Mesenchymal Stem Cell Defects; Cell stem cell; (7 January 2011) 8- 1: 31-45

43. Janbernd Kirschner, Thomas Brune, Manfred Wehnert, Jonas Denecke. p.S143F mutation in lamin A/C: A new phenotype combining myopathy and progeria; Annals of Neurology; (Jan 2005) Volume 57, Issue 1, pages 148-151. 44. Iannello S, Spina M, Prestipino M, Strano AM, Bellassai M, Politi G, Belfiore F. Familial Marfan's syndrome. A critical review and presentation of a clinical case; Minerva Med. 1996 May;87(5):217-35.

45. von Kodolitsch $Y$, Raghunath M, Nienaber CA. Marfan syndrome: prevalence and natural course of cardiovascular manifestations; Z Kardiol. 1998 Mar; $87(3): 150-60$

46. Jason B. Wheeler, John S. Ikonomidis, Jeffrey A. Jones. Connective Tissue Disorders and Cardiovascular Complications: The Indomitable Role of Transforming Growth Factor-Beta Signaling; Advances in Experimental Medicine and Biology Volume 802, 2014, pp 107-127

47. Nagesh CM, Patra S, Singh A, Badnur SC, Reddy B, Nanjappa MC. A patient with Marfan's syndrome presented with severe rheumatic mitral stenosis and successfully treated with percutaneous transmitral balloon commissurotomy - Report of first case; J Cardiovasc Dis Res. 2013 Dec;4(4):257-9. 48. Bruno L, Tredici S, Mangiavacchi M, Colombo V, Mazzotta GF, Sirtori CR. Cardiac, skeletal, and ocular abnormalities in patients with Marfan's syndrome and in their relatives. Comparison with the cardiac abnormalities in patients with kyphoscoliosis; Br Heart J. 1984 Feb;51(2):220-30.

49. De Backer J. Cardiovascular characteristics in Marfan syndrome and their relation to the genotype. Verh K Acad Ceneeskd Belg. 2009;71(6):335-71. PMID: 20232788;

50. Zipes, Libby Bonow Braunwald. Braunwald's Heart Disease A Textbook of Cardiovascular Medicine, Seventh Edition. United States of America: Elseview Saunders. (2005) p. 1894. ISBN 0-7216-0509-5.

51. Figueiredo S, Martins E, Lima MR, Alvares S.. Cardiovascular manifestations in Marfan syndrome; Rev Port Cardiol. 2001 Dec;20(12):1203-18. 52. J. Lamont Murdoch, Bryan A. Walker, Barry L. Halpern, Jan W. Kuzma, and Victor A. McKusick. Life Expectancy and Causes of Death in the Marfan Syndrome; N Engl J Med 1972; 286:804-808 April 13, 1972

53. Tracie E. Bunton, Nancy Jensen Biery, Loretha Myers, Barbara Gayraud, Francesco Ramirez, Harry C. Dietz. Phenotypic Alteration of Vascular Smooth Muscle Cells Precedes Elastolysis in a Mouse Model of Marfan Syndrome; Circulation Research. 2001; 88: 37-43

54. Takashi Haruki, Hiroshi Ito, Kensuke Sakata, Yurio Kobayashi et al. Bilateral axillary artery aneurysms after Bentall procedure in Marfan syndrome; Published online before print April 14, 2014. Asian Cardiovascular and Thoracic Annals April 14, 2014: 0218492314532278

55. Ertan Mayatepek, Thaddeus W. Kurczynski, Elizabeth S. Ruppert, James R. Hennessy, Ray A. Brinker and Beatrice N. French. Expanding the phenotype of the Proteus syndrome: A severely affected patient with new findings; American Journal of Medical Genetics; (March 1989) Volume 32, Issue 3, pages 402-406

56. Loffroy R, Rao P, Steinmetz E, Krausé D. Endovascular treatment of disseminated complex aortic vascular malformations in a patient with proteus syndrome. Ann Thorac Surg. 2010 Nov;90(5):e78. doi: 10.1016/j.athoracsur.2010.06.122.

57. Shaw C, Bourke J, Dixon J. Proteus syndrome with cardiomyopathy and a myocardial mass. Am J Med Genet. 1993 Apr 15;46(2):145-8.

58. B. Newman, A. H. Urbach, D. Orenstein, P. S. Dickman. Proteus syndrome: emphasis on the pulmonary manifestations; Pediatric Radiology; June 1994, Volume 24, Issue 3, pp 189-193
59. Badia MC, Chamarro R, Làinez JM, Piera A. Proteus syndrome with cerebral vascular malformations; Neurologia. 2006 Mar;21(2):88-91.

60. Hoeger PH, Martinez A, Maerker J, Harper Jl. Vascular anomalies in Proteus syndrome; Clin Exp Dermatol. 2004 May;29(3):222-30.

61. QI Ying Chun and XIE Xiao Hua. Hutchinson-Gilford Progeria Syndrome and its Relevance to Cardiovascular Diseases and Normal Aging; Biomedical and Environmental Sciences (besjournal.com); doi: 10.3967/0895-3988.2013.05.007 62. Brian C. Capell, Francis S. Collins, Elizabeth G. Nabel. Mechanisms of Cardiovascular Disease in Accelerated Aging Syndromes; Circulation Research; 2007; 101: 13-26

63. Baker PB, Baba N, Boesel CP. Cardiovascular abnormalities in progeria. Case report and review of the literature; Archives of Pathology a Laboratory Medicine [1981, 105(7):384-386; (PMID:6894691)

64. Ilyas S, llyas H, Hameed A, llyas M. Progeria syndrome with cardiac complications. J Pak Med Assoc. 2013 Sep;63(9):1182-5.

65. Norman Makous, Sidney Friedman, William Yakovac, Elizabeth P. Maris. Cardiovascular manifestations in progeria. Report of clinical and pathologic findings in a patient with severe arteriosclerotic heart disease and aortic stenosis; American Heart Journal Volume 64, Issue 3, September 1962, Pages 334-346

66. Elizabeth G. Nabel; Cardiovascular Insights from a Premature Aging Syndrome: A Translational Story; Trans Am Clin Climatol Assoc. 2012; 123: 221-226.

67. Toshio Ogihara, Takeshi Hata, Kiyoji Tanaka, Kenichiro Fukuchi, Yoshikatsu Tabuchi, Yuichi Kumahara. Hutchinson-Gilford progeria syndrome in a 45-year-old man; The American Journal of Medicine; Volume 81, Issue 1, July 1986, Pages 135-138

68. Michelle Olive, Ingrid Harten, Richard Mitchell, Jeanette K. Beers, Karima Djabali. Cardiovascular Pathology in Hutchinson-Gilford Progeria: Correlation With the Vascular Pathology of Aging; Arteriosclerosis, Thrombosis, and Vascular Biology. 2010; 30: 2301-2309.

69. William E. Stehbens, St.John Wakefield, Enid Gilbert-Barness, Robert E. Olson, Jeanne Ackerman. Histological and Ultrastructural Features of Atherosclerosis in Progeria; Cardiovascular Pathology; Volume 8, Issue 1, JanuaryFebruary 1999, Pages 29-39

70. I H Maumenee. The eye in the Marfan syndrome; Trans Am Ophthalmol Soc. 1981; 79: 684-733. PMCID: PMC1312201

71. John C S Dean. Marfan syndrome: clinical diagnosis and management; European Journal of Human Cenetics (2007) 15, 724-733

72. Aman Chandra, Victoria Ekwalla, Anne Child, and David Charteris. Prevalence of ectopia lentis and retinal detachment in Marfan syndrome; Acta Ophthalmologica; (February 2014) Volume 92, Issue 1, pages e82-e83 73. Ukponmwan CU. Ocular features and management challenges of Marfan's Syndrome in Benin City, Nigeria. Niger Postgrad Med J. 2013 Mar;20(1):24-8. PMID: 23661206.

74. Konradsen TR, Zetterström C. A descriptive study of ocular characteristics in Marfan syndrome; Acta Ophthalmol. 2013 Dec;91(8):751-5. doi: 10.1111/ aos.12068. Epub 2013 Feb 7.

75. Inge De Becker, David J. Gajda, Enid Gilbert-Barness and M. Michael Cohen Jr. Ocular manifestations in Proteus syndrome; American Journal of Medical Cenetics; (June 2000) Volume 92, Issue 5, pages 350-352.

76. Evrydiki A. Bouzas, Donna Krasnewich, Michael Koutroumanidis, Alexandros Papadimitriou. Ophthalmologic Examinadon in the Diagnosis of Proteus Syndrome; Ophthalmology; Volume 100, Issue 3, March 1993, Pages 334-338; 77. Trivedi D, Lee SY, Brundler MA, Parulekar MV. Fibrous tumor of the superior oblique tendon in Proteus syndrome. J AAPOS. 2013 Aug;17(4):420-2. 78. Sánchez-López M, Martínez-Fernández R, Santamaría-Carro A. Ocular manifestations in Proteus syndrome; Arch Soc Esp Oftalmol. 2007 Mar;82(3):1758.

79. Sheard RM, Pope FM, Snead MP. .A novel ophthalmic presentation of the Proteus syndrome.; Ophthalmology. 2002 Jun;109(6):1192-5; PMID: 12045066 
80. Bouzas EA, Krasnewich D, Koutroumanidis M, Papadimitriou A, Marini JC. Ophthalmologic examination in the diagnosis of Proteus syndrome; Ophthalmology. 1993 Mar; 100(3):334-8; PMID: 8460002

81. Gilbert-Barness E, Cohen MM Jr, Opitz JM. Multiple meningiomas, craniofacial hyperostosis and retinal abnormalities in Proteus syndrome; Am J Med Cenet. 2000 Jul 31;93(3):234-40; PMID: 10925389

82. Shivcharan L Chandravanshi, Ashok Kumar Rawat, Prem Chand Dwivedi, and Pankaj Choudhary. Ocular manifestations in the Hutchinson-Gilford progeria syndrome; PMC ID: PMC3214428; Indian J Ophthalmol. 2011 Nov-Dec; 59(6): 509-512.

83. Robert C. Moehlig. PROGERIA WITH NANISM AND CONGENITAL CATARACTS IN A FIVE YEAR OLD CHILD; JAMA. 1946;132(11):640-642.

84. V. V. Neroev, M. M. Archipova, L. E. Bakeeva, A. Zh. Fursova. Mitochondria-targeted plastoquinone derivatives as tools to interrupt execution of the aging program. 4. Age-related eye disease. SkQ1 returns vision to blind animals; Biochemistry (Moscow) December 2008, Volume 73, Issue 12, pp $1317-1328$

85. Debette S, Germain DP. Neurologic manifestations of inherited disorders of connective tissue; Handb Clin Neurol. 2014;119:565-76.

86. Robert J. Wityk; Carla Zanferrari; Stephen Oppenheimer; Neurovascular Complications of Marfan Syndrome: A Retrospective, Hospital-Based Study; Stroke. 2002; 33: 680-684

87. J.S.P. van den Berg, M. Limburg, R.C.M. Hennekam. Is Marfan Syndrome Associated With Symptomatic Intracranial Aneurysms?; Stroke. 1996; 27: 1012

88. R E Pyeritz, E K Fishman, B A Bernhardt, and S S Siegelman. Dural ectasia is a common feature of the Marfan syndrome; Am J Hum Genet. Nov 1988; 43(5): 726-732; PMCID: PMC1715546

89. Iris Schrijver, Wouter I. Schievink, Maurice Codfrey, Fredric B. Meyer, and Uta Francke. Spontaneous spinal cerebrospinal fluid leaks and minor skeletal features of Marfan syndrome: a microfibrillopathy; Journal of Neurosurgery; March 2002 / Vol. 96 / No. 3 / Pages 483-489

90. R J Davenport, S J Chataway, C P Warlow. Spontaneous intracranial hypotension from a CSF leak in a patient with Marfan's syndrome; J Neurol Neurosurg Psychiatry 1995;59:516-519

91. W. Eugene Stern M.D; Dural ectasia and the Marfan syndrome; Journal of Neurosurgery; August 1988 / Vol. 69 / No. 2 / Pages 221-227

92. Tena Rosser, Julie Finkel, Gilbert Vezina, Massoud Majd. Case Report and Review of the Literature: Postural Headache in a Child With Marfan Syndrome; J Child Neurol February 2005 vol. 20 no. 2 153-155

93. J. D. Nelson. The Marfan Syndrome, with Special Reference to Congenital Enlargement of the Spinal Canal; The British Journal of Radiology: Volume 31 Issue 370, October 1958

94. Ahn, Nicholas U. Sponseller, Paul D, Ahn, Uri M; Nallamshetty, Leelakrishna BS; Kuszyk, Brian S; Zinreich, S. James et al. Case Study: Dural Ectasia Is Associated With Back Pain in Marfan Syndrome; Spine: 15 June 2000 - Volume 25 - Issue 12 - pp 1562-1568

95. P. D. Griffiths, R. J. Welch, D. Gardner-Medwin A. Gholkar, V. McAllister. The Radiological Features of Hemimegalencephaly Including Three Cases Associated with Proteus Syndrome; Neuropediatrics 1994; 25(3): 140-144

96. Halisson Bastosa, Paula Fabiana Sobral da Silvaa, Marco Antônio Veloso de Albuquerquea, Adriana Mattosa, Rudimar Santos Riesgob, Lygia Ohlweilerc. Proteus syndrome associated with hemimegalencephaly and Ohtahara syndrome: Report of two cases; Seizure; Volume 17, Issue 4, June 2008, Pages 378-382

97. Flemming Skovby, John M. Graham Jr., Stig Sonne-Holm, Dr. M. Michael, Cohen Jr. et al Compromise of the spinal canal in Proteus syndrome. American Journal of Medical Cenetics; Volume 47, Issue 5, pages 656-659, 1 October 1993

98. Neil J. White, David D. Cochrane, and Richard Beauchamp. Paraparesis caused by an angiolipomatous hamartoma in an adolescent with Proteus syndrome and scoliosis; Journal of Neurosurgery: Pediatrics; September 2005 / Vol. 103 / No. 3 / Pages 282-284

99. R B Dietrich, D E Glidden, G M Roth, R A Martin and D S Demo. The Proteus syndrome: CNS manifestations. American Journal of Neuroradiology: DOI: AJNR 1998 19: 987-990;

100. Sherman McCall, Magda I. Ramzy, Joel K. Cure and Dr. G. S. Pai. Encephalocraniocutaneous lipomatosis and the Proteus syndrome: Distinct entities with overlapping manifestations; American Journal of Medical Genetics: Volume 43, Issue 4, pages 662-668, 1 July 1992

101. Sayama K.a, Hato N.b, Matsuda O.c, Shiraishi S.a, Miki Y.a et al. Case Report: Proteus Syndrome: ISSN: 1018-8665: Dermatology 1994;189:392-395 102. Manquillo A, Martínez-Mena J, Quintana P, Paradinas F, Sáez J, Revilla C, Galán JM. Neurophysiological aspects of Proteus syndrome. Et al. Rev Neurol. 1997 Oct;25(146):1572-4.

103. Nicole J. Ullrich, Mark W. Kieran, David T. Miller. Neurologic features of Hutchinson-Gilford progeria syndrome after lonafarnib treatment. Neurology July 30, 2013 vol. 81 no. 5 427-430

104. Marek Mandera, Dawid Larysz, Jacek Pajak, Andrzej Klimczak. Epidural hematomas in a child with Hutchinson-Gilford progeria syndrome; Child's Nervous System: January 2003, Volume 19, Issue 1, pp 63-65

105. M Plasilova, C Chattopadhyay, P Pal, N A Schaub, S A Buechner, Hj Mueller, P Miny, A Chosh, K Heinimann. Homozygous missense mutation in the lamin $A / C$ gene causes autosomal recessive Hutchinson-Gilford progeria syndrome; Letters to JMG; J Med Genet 2004;41:609-614

106. Gordon LB, Brown WT, Collins FS. Hutchinson-Gilford Progeria Syndrome. 2003 Dec 12 [Updated 2015 Jan 8]. In: Pagon RA, Adam MP, Ardinger HH, et al., editors. GeneReviews $₫$ [Internet]. Seattle (WA): University of Washington, Seattle; 1993-2015.

107. James R. Gossa, Donna Beer Stolzb, d, Andria Rasile Robinsonc. Premature aging-related peripheral neuropathy in a mouse model of progeria: Mechanisms of Ageing and Development; Volume 132, Issues 8-9, AugustSeptember 2011, Pages 437-442

108. V.M. Silveraa, L.B. Gordonb,d,e, D.B. Orbacha, S.E. Campbellf, J.T. Machane,g,h and N.J. Ullrichc et al Imaging Characteristics of Cerebrovascular Arteriopathy and Stroke in Hutchinson-Gilford Progeria Syndrome; Doi: 10.3174/ ajnr.A3341; AJNR 2013 34: 1091-1097

109. J R Wood, D Bellamy, A H Child, K M Citron. Pulmonary disease in patients with Marfan syndrome; Thorax 1984;39:780-784

110. Edward M. Dwyer Jr, and Frank Troncale. Spontaneous Pneumothorax and Pulmonary Disease in the Marfan Syndrome: Report of Two Cases and Review of the Literature; Ann Intern Med. 1965;62(6):1285-1292.

111. John R. Hall, Reed E. Pyeritz, David L. Dudgeon, J. Alex Haller Jr. Pneumothorax in the Marfan Syndrome: Prevalence and Therapy; The Annals of Thoracic Surgery Volume 37, Issue 6, June 1984, Pages 500-504

112. Teoh PC. Bronchiectasis and spontaneous pneumothorax in Marfan's syndrome; Chest. 1977 Nov;72(5):672-3.

113. M. E. Foster and D. R. Foster. Bronchiectasis and Marfan's syndrome; Postgrad Med J. Oct 1980; 56(660): 718-719. PMCID: PMC2426010

114. E A Streeten; E A Murphy; R E Pyeritz. Pulmonary function in the Marfan syndrome; Chest. 1987;91(3):408-412. doi:10.1378/chest.91.3.408

115. J A Turner and N N Stanley. Fragile lung in the Marfan syndrome; Thorax. Dec 1976; 31(6): 771-775. PMCID: PMC470509

116. Andrew Jabbour, Saman Zaman, Tevfik Ismail, Sanjay Prasad, Prof Raad Mohiaddin. Profound pectus excavatum in Marfan's syndrome; The Lancet, Volume 379, Issue 9815, Page 557, 11 February 2012

117. Patricia L. Gordon, R. Sid Wilroy, Olga E. Lasater and Dr. M. Cohen Michael Jr. Neoplasms in proteus syndrome: American Journal of Medical Cenetics: (May 1995) Volume 57, Issue 1, pages 74-78, 22

118. Rajeeva R Raju, William R Hart, David K Magnuson, Janet R Reid and Douglas $G$, Rogers. Cenital Tract Tumors in Proteus Syndrome: Report of a Case of Bilateral Paraovarian Endometrioid Cystic Tumors of Borderline Malignancy 
and Review of the Literature; Mod Pathol 2002;15(2):172-180

119. Prasad Narayan, Rangaswamy Dharshan, Gupta Amit, Sharma Raj Kumar, Bhadauria Dharmender and Kaul Anupama. Distal renal tubular acidosis in a boy with Proteus syndrome; Kidney International (2013) 83, 1209-1210 120. Huang S, Liang Y, Wu W, Fu X, Liao L, Luo X. Analysis of a case with typical Hutchinson-Gilford progeria syndrome with scleroderma-like skin changes and review of literature. Zhonghua Er Ke Za Zhi. 2014 Feb;52(2):112-6.

121. Rork JF, Huang JT, Gordon LB, Kleinman M, Kieran MW, Liang MG. Initial cutaneous manifestations of hutchinson-gilford progeria syndrome; Pediatr Dermatol. 2014 Mar;31(2):196-202.

122. A. Harell Steinberg, A. Szeinberg, and B. E. Cohen. Amino-aciduria and Hypermetabolism in Progeria; Arch Dis Child. Oct 1957; 32(165): 401-403. PMCID: PMC2012178

123. Delahunt B, Stehbens WE, Gilbert-Barness E, Shozawa T, Rüger BM. Progeria kidney has abnormal mesangial collagen distribution; Pediatr Nephrol. 2000

124. Graul-Neumann LM, Kienitz T, Robinson PN, Baasanjav S, Karow B, Gillessen-Kaesbach G, Fahsold R, Schmidt H, Hoffmann K, Passarge E; Marfan syn- drome with neonatal progeroid syndrome-like lipodystrophy associated with a novel frameshift mutation at the 3 ' terminus of the FBN1-gene.; American Journal of Medical Genetics Part A > Vol 152A Issue $11>$ Abstract

125. Coldblatt J, Hyatt J, Edwards C, Walpole I. Further evidence for a marfanoid syndrome with neonatal progeroid features and severe generalized lipodystrophy due to frameshift mutations near the $3^{\prime}$ end of the FBN 1 gene. American Journal of Medical Cenetics Part A; (April 2011) Volume 155, Issue 4, pages $717-720$

126. Takenouchi T, Hida M, Sakamoto Y, Torii C, Kosaki R, Takahashi T, Kosaki; Severe congenital lipodystrophy and a progeroid appearance: Mutation in the penultimate exon of $\mathrm{FBN}_{1}$ causing a recognizable phenotype. American Journal of Medical Cenetics Part A; Volume 161, Issue 12, pages 3057-3062 127. Caux F, Dubosclard E, Lascols 0 , Buendia B, Chazouillères 0 , Cohen A et al. A new clinical condition linked to a novel mutation in lamins $A$ and $C$ with generalized lipoatrophy, insulin-resistant diabetes, disseminated leukomelanodermic papules, liver steatosis, and cardiomyopathy. J Clin Endocrinol Metab. 2003 Mar;88(3):1006-13.

\section{Acknowledgments}

None

Conflict of Interest Statement at Funding

The author has no funding, financial relationships or conflicts of interest to disclose.

Author Contributions

Conception and design the work/idea, Collect data/obtaining results, Critical revision of the manuscript, Approval of the final version: TB

Cite as:

Biswas T. Mutation in Cenes FBN1, AKT1, and LMNA: Marfan Syndrome, Proteus Syndrome, and Progeria Share Common Systemic Involvement. Int J Med Students. 2015 Apr-Aug;3(2):92-101. 